\title{
National Identifications and Attitudes to National Ingroups and Outgroups amongst Children living in the Basque Country
}

\author{
Luixa Reizábal*, Jose Valencia* \& Martyn Barrett** \\ * Faculty of Psychology, University of the Basque Country \\ ** Department of Psychology, University of Surrey, UK
}

Running head: National identifications and attitudes in Basque children

Address for correspondence: Martyn Barrett, Department of Psychology, University of Surrey, Guildford, Surrey GU2 7XH, UK. Email: m.barrett@ surrey.ac.uk. Tel: 01483686862. Fax: 01483-689553.

Acknowledgements: The research reported in this paper was supported by two grants received from the University of the Basque Country (Grant No. UPV 227.231ha030/98) and the Basque Government (Grant No. PI 1999-103) and by a grant received from INTAS (Grant No. OPEN-97-1363) which was awarded to the Universities of Surrey, Dundee, Girona, Malaga and Basque Country and to the Russian Academy of Sciences, Kharkov State University, the Georgian Institute of Psychology and the Azerbaijan Pedagogical Institute for Russian Language and Literature. We are very grateful to the following colleagues who have contributed to this programme of research: Mark Bennett, Ignasi Vila, Almudena Giménez de la Peña, Tatiana Riazanova, Valentina Pavlenko, Giorgi Kipiani and Rauf Karakazov. 
National Identifications and Attitudes to National Ingroups and Outgroups amongst

Children living in the Basque Country

\begin{abstract}
This study investigated the development of national identification in children growing up in the Basque Country. The sample consisted of 246 children aged 6, 9, 12 and 15 years old who belonged to three linguistic subgroups: children who spoke only Basque with their parents in their home, children who spoke only Spanish in their home, and children who spoke both Basque and Spanish in their home. It was found that national identifications differed in the three linguistic subgroups. Furthermore, the three subgroups exhibited different evaluations of, and feelings towards, the national ingroup and a number of national outgroups. The positive and affective distinctiveness ascribed to the Basque and Spanish national groups was correlated with the strength of identification with the Basque and Spanish groups respectively. The attitudes towards national outgroups which were exhibited by these children did not show any changes as a function of age. It is argued that the cognitive-developmental account of the development of national attitudes is unable to explain the patterns of findings which were obtained, but that social identity theory can explain the correlation between the strength of national identification and the positive and affective distinctiveness which was ascribed to the ingroup.
\end{abstract}

Keywords: national identity, national attitudes, positive distinctiveness, social identity 
National Identifications and Attitudes to National Ingroups and Outgroups amongst Children living in the Basque Country

This paper reports a study which investigated the development of national identification in children who are growing up in the Basque Country in the Spanish State. The study focused in particular upon the relationship between the children's own national identifications and the evaluative and affective attitudes which they exhibited towards their national ingroup and a number of national outgroups.

Previous studies of children's national identification have found that children usually begin to categorise themselves as members of their own national group from about 5 or 6 years of age, when they also start to express attitudes towards the members of other national groups (Barrett, 1996, 2001, in press; Jahoda, 1962; Jaspers, van de Geer, Tajfel \& Johnson, 1972; Johnson, Middleton \& Tajfel, 1970; Lambert \& Klineberg, 1967; Middleton, Tajfel \& Johnson, 1970; Piaget \& Weil, 1951; Tajfel \& Jahoda, 1966; Tajfel, Jahoda, Nemeth, Campbell \& Johnson, 1970). During subsequent years, children's knowledge of the people who belong to different national groups expands considerably, and by 10 or 11 years of age children are able to produce detailed descriptions of the characteristics exhibited by members of their own and other national groups, including their typical physical features and appearance, clothing, language, behavioural habits, psychological traits, and political and religious beliefs (Barrett \& Short, 1992; Lambert \& Klineberg, 1967; Piaget and Weil, 1951).

The acquisition of this knowledge about national groups during middle childhood is typically accompanied by the acquisition of a systematic preference for members of the national ingroup over members of national outgroups (Barrett, 2001, in press; Bennett, Lyons, Sani \& Barrett, 1998; Lambert \& Klineberg, 1967; Tajfel et al., 1970). However, some national outgroups may still be positively liked and evaluated, although to a lesser extent than the ingroup (Barrett \& Short, 1992; Johnson et al., 1970; Lambert \& Klineberg, 1967; Middleton et al., 1970). Once a relative order of liking of national outgroups has been established, this order tends to remain stable and consistent across the remaining childhood years (Barrett \& Short, 1992; Jaspers et al., 1972; Johnson et al., 1970). However, the overall degree of liking of all national outgroups tends to increase between 5 and 11 years of age (Barrett \& Short, 1992; Lambert \& Klineberg, 1967). After 11 years of age, this general increase in positive regard for other national groups typically levels out (Lambert \& Klineberg, 1967).

It is noteworthy that this increase in positive regard for national outgroups occurs at the same time as the increase in positive regard for ethnic outgroups amongst white majority group children. It has been argued that negativity towards ethnic outgroups in such children peaks at about 6 years of age, and declines between 6 and 12 years of age (Aboud, 1988; Bigler \& Liben, 1993; Davey 1983; Katz \& Zalk, 1978; Vaughan, 1964; Williams \& Morland, 1976). Investigating this trend in the development of ethnic attitudes using an adjective attribution task, Doyle, Beaudet, and Aboud (1988), Powlishta, Serbin, Doyle, and White (1994) and Doyle and Aboud (1995) found that, at the age of 5 or 6 , children attribute mainly positive adjectives to members of their own ethnic group, and mainly negative adjectives to members of other ethnic groups. Between 6 and 12 years of age, this polarisation in the attribution of adjectives decreases, as children gradually come to attribute both positive and negative attributes to both the ethnic ingroup and outgroups. Barrett, Wilson, and Lyons (1999a) report a similar developmental trend in children's attributions to national groups. They 
asked 5-11-year-old English children to attribute adjectives to their own national group and to Americans and Germans. With increasing age, there was an increase in the number of negative adjectives attributed to English people, and an increase in the number of positive adjectives attributed to Americans and Germans. The net result was an overall reduction in the positive bias towards the ingroup across this age range. However, ingroup favouritism was still exhibited by the children at all ages.

Doyle et al. (1988) argue that the developmental changes which occur to ethnic attitudes across middle childhood are due to the increasing recognition across this age range that all ethnic groups contain all kinds of people exhibiting both positive and negative characteristics. Doyle and Aboud (1995) further argue that this shift in the conceptualisation of ethnic groups is itself based upon underlying socio-cognitive changes in the way that large-scale social groups are conceptualised, involving perceptions of greater variability within social groups and greater similarity between social groups. Barrett et al.'s (1999a) finding that a similar developmental trend occurs in children's attributions to national groups is consistent with this hypothesis that the reduction in ingroup bias during middle childhood is a consequence of a general cognitive-developmental shift in children's understanding of large-scale social groups.

In the present study, 6- to 15-year-old Basque children were asked to attribute adjectives to their own national ingroup and to a number of national outgroups. One of the aims of the study was to explore whether these children also exhibit an increase in positivity towards national outgroups, and an increase in negativity towards their own national ingroup, between the ages of 6 and 12. If such trends in the development of intergroup attitudes are exhibited by this (hitherto unstudied) group of children, and in relation to national rather than ethnic groups, this would bolster confidence in the claim that changes in national attitudes across this age range are a consequence of a general cognitive-developmental change which is applied contemporaneously to all large-scale social groups (and not just ethnic groups).

However, in addition, and unlike the previous studies by Doyle et al. (1988), Powlishta et al. (1994), Doyle and Aboud (1995), and Barrett et al. (1999a), the present study also measured the strength of identification with the ingroup. Previous research with both adults and children has revealed that attitudes to ingroups and outgroups can be a product of many different factors, including the strength of subjective identification with the ingroup, the individual's beliefs about the nature of the prevailing group boundaries, and about the relative status of the ingroup (e.g. see Bennett \& Sani, in press). The present study explored the particular suggestion that attitudes to ingroups and outgroups are a product of the strength of subjective identification with the ingroup.

The underlying argument here, originally derived from Social Identity Theory (SIT) (Tajfel, 1978; Tajfel \& Turner, 1986), is based upon the observation that individuals belong to many different social groups (e.g. gender, national, ethnic, social class, etc.) and that these social group memberships may sometimes be internalised as part of an individual's self-concept. SIT postulates that when this occurs, individuals strive to obtain a sense of positive self-worth from their membership of the ingroup. Consequently, in constructing representations of the ingroup and relevant outgroups, dimensions of comparison are chosen which produce more favourable representations of the ingroup than of outgroups, resulting in ingroup favouritism or outgroup denigration or both. The positive distinctiveness which is attributed to the ingroup produces positive self-esteem. However, in order for these effects to occur, the 
individual needs to have internalised a social group membership as part of his or her self-concept, that is, the individual must subjectively identify with that category. If an individual's subjective identification with a particular social group is weak or absent, then these effects will not occur. The prediction that there should be a correlation between the strength of identification and attitudes to the ingroup and outgroups has been investigated extensively in relationship to adults (see, for example, Abrams, 1990; Aharpour \& Brown, 2000; Branscombe \& Wann, 1994; Grant, 1992, 1993; Hinkle \& Brown, 1990; Kelly, 1988; Mummendey, Klink \& Brown, 2001; Perreault \& Bourhis, 1998), but rarely in relationship to children. Consequently, the present investigation measured the strength of national identification in the children who were studied, in order to ascertain whether this variable was related to the positive distinctiveness attributed to the ingroup over the outgroups.

The study was conducted with children who are growing up in the Basque Country, a part of which is located in the Spanish State. The Basque Country provides a particularly interesting context in which to explore these issues. This is because national identity is constructed in very different ways by different individuals living in this country. The Basque language (which is also called Euskara) is one of the oldest languages in Europe, but its use was forbidden for 40 years (during the years of the Franco regime), when Spanish was the only official language which could be spoken in the Basque Country. Because of immigration from some regions of Spain, Basque is today spoken only by about $29 \%$ of the population of the Basque Country. The Basque Country itself is divided between the French and the Spanish States. That part of the country which is located in the Spanish State has a strong nationalist movement, and a strong social perception of being different from the other parts of the Spanish State. However, this perception is not homogeneous for a number of reasons, one of the most important being that a large proportion of the population of the Basque Country immigrated from some parts of the Spanish State, mainly from Extremadura. During Franco's regime, all Basque institutions as well as the use of the language and Basque symbols were forbidden. When Franco died, the Basque Country achieved a certain level of autonomy. However, the right to self-determination, one of the most salient principles for a large part of the population, was not granted by the Spanish government. Thus many Basque individuals are concerned to defend the Basque Country's cultural and linguistic identity.

Sociolinguistic studies have revealed that the use of language by adults in the Basque Country is related to their sense of national identification: adults who regularly use the Basque language in their everyday interactions tend to exhibit a strong positive identification with the Basque identity and an absence of identification with the Spanish identity, while those who use the Spanish language instead tend to exhibit a low level of identification with the Basque identity and a strong positive identification with the Spanish identity (Azurmendi, Garcia \& Gonzalez, 1998; Elejabarrieta, 1994; Valencia et al., in press). These findings are consistent with the findings of other studies which have shown that there is often a close relationship between the use of language and the formation of differentiated identity groups, and that different identity groups exhibit different linguistic attitudes (Barrett et al., 1999b; Giles, Bourhis \& Taylor, 1977; Sachdev \& Bourhis, 1990; Vila, 1996). Because of the availability of the two languages (i.e. Spanish and Basque) in the Basque Country, which are themselves linked to different patterns of national identification amongst adults, the present study aimed to examine whether the national identifications which are acquired by children who are growing up in the Basque County also vary as a function of the language(s) which are spoken with the 
parents in the family home.

There are three possible situations which may pertain in the family home: parents may speak only Spanish, only Basque, or both Spanish and Basque with their children. Because parents' choice of language is itself likely to be linked to the parents' own national identifications, the prediction is that children who are brought up by their parents speaking only Spanish, only Basque, or both Spanish and Basque within the home are themselves likely to acquire different patterns of national identification (through their exposure to, and internalisation of, different patterns of national attitudes, discourse and practices from their parents).

It was therefore predicted that there would be systematic variation in the national identifications exhibited by the children in this study, as a function of the language(s) spoken with the parents in the home environment. In one sense, this prediction was trivial (being equivalent to the prediction that children growing up in different national contexts will acquire different patterns of national identification). However, precisely because it was expected that there would be such variability in the national identifications exhibited by these children, it was reasoned that these data would provide a particularly useful test of the robustness of both the cognitivedevelopmental prediction (that there would be a reduction in ingroup bias through middle childhood) and the social-identity prediction (that there would be a significant correlation between the strength of national identification and the positive distinctiveness ascribed to the ingroup). If these two predictions were to be upheld, despite the variability in the specific contents of the national identification systems being acquired by the children, it was reasoned that these effects must be especially robust.

\section{Method \\ $\underline{\text { Sample }}$}

The participants were 246 children aged $6,9,12$ and 15 years old living in the Basque Country (there were approximately the same number of children at each age: 63, 63, 62 and 58 children, respectively). 103 children were male, and 143 were female. The linguistic home situation was assessed by asking the child what language(s) he/she used to talk with his/her parents at home. Depending upon the answer, participants were categorised into three linguistic subgroups. These three subgroups were: (a) a Spanish group, which consisted of children who spoke only Spanish at home ( $\mathrm{N}=97)$; (b) a Basque group, which consisted of children who spoke only Basque at home ( $\mathrm{N}=87)$; and (c) a "bilingual" group, which consisted of children who spoke both Spanish and Basque at home $(\mathrm{N}=62)$.

Procedure

Each child was interviewed individually in a quiet room made available in their school. The language in which the interview was conducted (Spanish or Basque) was the language which the child used spontaneously to speak to the interviewer at their initial meeting. After establishing rapport with the child, it was explained that the interviewer was interested in finding out what the child thought about certain things. Reassurance was given that this was not a test, that there were no right or wrong answers, and that no one other than the interviewer would know what they had said. The tasks which the children were given required the selection and organising of words, which were printed on cards. The interviewer was alert to possible weaknesses in the 
children's reading skills and assistance in reading the cards was provided whenever this was judged to be necessary. The children completed all the tasks in the same order.

Due to fact that Spanish (but not Basque) has feminine and masculine adjective suffixes, three versions of the interview schedule and sets of response cards were prepared in advance, two in Spanish (one in each gender) and one in Basque. Just one of these interview schedules and set of response cards was used with each individual child, depending on language (i.e. Basque or Spanish) and gender (i.e. male or female, if the Spanish cards were used). The interview schedule and response cards were initially prepared in English. They were then translated into Spanish and Basque independently by two separate translators. The two translations were compared, and any discrepancies resolved by discussion. The agreed instrument was then backtranslated into English by a third independent translator, and the backtranslation was compared with the original English instrument in order to ensure that no alterations in meaning had occurred as a result of the translation process.

During the course of the interview, the following variables were measured.

\section{Self-categorisations}

The children's self-categorisations were measured using two different methods. In the first method, a set of 15 cards was presented to the child. These cards contained the following descriptive terms: 6 years old, 9 years old, 12 years old, 15 years old, girl, boy, city identity (i.e. the name for the people who live in the city or town in which the child lived), Basque, Extremadurian, Spanish, European, English, French, Italian and German. The interviewer spread these cards out randomly on the table and said to the child: Look at these cards. All these words can be used to describe people. Which ones do you think could be used to describe you? You can choose as many as you like. Shall I help you to read them? After the child had selected the cards that she/he thought described herself/himself, the interviewer put away the rejected cards and spread out the ones which had been selected by the child on the table in a random order. The child was then asked: So all these cards describe you. But if you had to choose only one of these cards because it was the most important for you, which one would you choose? The chosen card was removed from the set, and the child was then asked to choose the most important card out of those remaining. This procedure was repeated until a rank order of importance had been determined for all of the selected cards.

The second method which was used to measure the children's self-categorisations was the following open-ended question: If you were in America and someone asked you "where are you from?", what would you say? The children's answers were recorded verbatim.

\section{National identifications}

The children's national identifications were measured using three sets of cards. The first set of four cards concerned Spanish identification. The cards contained the following text: very Spanish, a little bit Spanish, not at all Spanish, don't know. The cards were spread out in front of the child, with the left-right ordering of the first three cards counterbalanced across successive children. The child was then asked: Which one of these cards do you think best describes you? The child's choice was recorded. The second set of four cards concerned Basque identification and contained the following text: very Basque, a little bit Basque, not at all Basque, don't know. The same procedure was used as in the case of the Spanish identification cards, with the children again being asked 
to select the card which best described them. The third set of six cards contained the following text: Basque, more Basque than Spanish, both Basque and Spanish, more Spanish than Basque, Spanish, don't know. Here, the left-right ordering of the first five cards was counterbalanced across successive children. Once again, the child was asked to choose the card which they thought best described them.

Evaluations of, and feelings about, the members of the national ingroup and selected national outgroups

Two methods were used to assess the children's evaluations of, and feelings about, national ingroups and outgroups. The first method elicited the children's descriptions of seven specific groups: Basque, Extremadurian, Spanish, French, Italian, British and German people (Extremadurian was included here as it is a salient outgroup for many Basque people). The children were first presented with a set of 12 cards, each of which contained one of the following terms: clean, dirty, friendly, unfriendly, clever, stupid, hardworking, lazy, happy, sad, honest and dishonest. These particular terms were chosen on the basis of previous studies which have shown that these are all terms which children themselves produce spontaneously when asked to describe national and ethnic groups, they are terms which children are able to comprehend in reference to national and ethnic groups, and the dimensions which they capture are of known relevance to children's descriptions of national and ethnic groups (Barrett \& Short, 1992; Doyle et al., 1988; Lambert \& Klineberg, 1967). The cards were presented in a different randomised order to each child. The child was then asked: Here are some cards with words on them that can be used to describe people. So, we can say that some people are ... (word written on first card; first card then removed and second one shown to child). And some people are ... (word written on second card). Right? Now, what I want you to do is go through all these words one by one, and I want you to sort out those words which you think can be used to describe X people. Can you do that for me please? Sort out the words which you think describe X people. The child was asked to perform this task seven times, once in relationship to each of the seven national groups. The national groups were administered in a different randomised order for each individual child. It should be noted that this method allows the child to reject any positive or negative adjective which he or she believes to be inapplicable to a particular target group, and allows the child to assign adjectives independently to ingroups and to outgroups. Thus, this method does not confound the measurement of ingroup bias and outgroup rejection, unlike various other methods which have been used in the past to measure children's intergroup attitudes (cf. the discussion by Cameron, Alvarez, Ruble \& Fuligni, 2001).

The second method which was used was the following. Immediately after completing the adjective sorting task for a particular national group, and before moving on to the next national group, the child was asked: Now, I just want to ask you one more thing about X people. Do you like or dislike X people? If the child said that he/she liked or disliked the group, the interviewer then spread out on the table a set of cards containing the words: dislike a lot, dislike a little, don't know, like a little, like a lot. The child was then asked: And how much do you like/dislike them? Choose your answer from these cards. The procedure was repeated for each of the seven national groups. 


\section{Results \\ $\underline{\text { Self-categorisations }}$}

The first-choice self-descriptions that were chosen as the most important by the children on the initial task measuring self-categorisation are shown in Table 1, broken down according to linguistic group. In order to ascertain whether there was an association between the children's first choices on this task and either their linguistic group or their age, a hierarchical log linear analysis was conducted. This revealed no significant associations involving age, but a significant association between response and linguistic group $\left(\chi^{2}(10)=38.61, p<0.001\right)$. Children belonging to the Basque and bilingual groups selected Basque as their first-choice identity more frequently than children belonging to the Spanish group. The Spanish identity was chosen first only by a relatively small proportion of the Spanish speakers, and this category was not chosen first by any members of the other two linguistic groups. The European category was not selected as their first choice by many participants in any of the linguistic groups.

Gender was clearly an important category for all three groups.

INSERT TABLES 1 AND 2 ABOUT HERE

The second method which was used to measure self-categorisation was by means of the children's answers to the question If you were in America and someone asked you "where are you from?", what would you say? A hierarchical log linear analysis revealed an association between response and linguistic group $\left(\chi^{2}(10)=17.77\right.$, $p<0.06)$, and between response and age $\left(\chi^{2}(15)=123.00, p<0.0001\right)$. The data relating to the association between response and linguistic group are shown in Table 2 . The Spanish speakers were less likely to respond with Basque Country than the Basque speakers and the bilinguals, and were instead more likely than the other two groups to respond with Spain.

The association between response and age group was due to a decline with age in the frequency of mentions of the city (from $88.9 \%$ of responses at 6 years of age to $12.1 \%$ of responses at 15 years of age), an increase with age in the frequency of mentions of the Basque Country (from 3.2\% at 6 years to $57 \%$ at 15 years), and an increase with age in the frequency of mentions of Spain (from $6.3 \%$ at 6 years to $27.6 \%$ at 15 years). The 3-way association between linguistic group, age and response was not significant.

\section{Spanish identification}

\section{$\underline{\text { National identifications }}$}

A hierarchical log linear analysis revealed highly significant associations between response and linguistic group $\left(\chi^{2}(8)=42.94, p<0.0001\right)$ and between response and age $\left(\chi^{2}(12)=63.42, p<0.0001\right)$ on the Spanish identification task. The data are shown in Table 3. As far as the relationship between linguistic home situation and Spanish identification was concerned, while the not at all Spanish answer was chosen by a large proportion of the Basque speakers and bilinguals, the Spanish-speaking group were more likely to choose the very Spanish response.

\section{INSERT TABLE 3 ABOUT HERE}

The association with age was due to the frequency of don't know answers declining as a function of age from $41.3 \%$ of answers amongst the 6-year-olds to $5.2 \%$ of answers amongst the 15-year-olds, the frequency of not at all Spanish responses increasing with age from $12.7 \%$ amongst the 6 -year-olds to $34.5 \%$ amongst the 15 -year- 
olds, and the frequency of a little bit Spanish responses increasing with age from $17.5 \%$ amongst the 6-year-olds to $50.0 \%$ amongst the 15 -year-olds. Once again, the 3-way association between linguistic group, age and response was not significant.

\section{Basque identification}

A hierarchical log linear analysis of the responses on the Basque identification task also revealed highly significant associations between response and linguistic group $\left(\chi^{2}(6)=53.57, p<0.0001\right)$ and between response and age $\left(\chi^{2}(9)=33.09, p<0.0001\right)$. The data are shown in Table 4. As far as the relationship between linguistic home situation and Basque identification was concerned, although very Basque was chosen the most frequently by all three linguistic groups, there were differences between the three groups. In both the Basque and the bilingual groups, this was by far the most frequent response ( $85.1 \%$ and $74.8 \%$ respectively), whereas this response was only chosen by the Spanish group $43.3 \%$ of the time. In addition, $14.4 \%$ of the Spanish speakers chose not at all Basque, whereas a much lower percentage of children in the Basque and bilingual groups chose this answer.

\section{INSERT TABLE 4 ABOUT HERE}

The association with age was due to the frequency of don't know answers declining as a function of age from $15.9 \%$ of answers amongst the 6-year-olds to $1.7 \%$ of answers amongst the 15-year-olds, and the frequency of a little bit Basque responses increasing with age from $6.3 \%$ amongst the 6-year-olds to $22.4 \%$ amongst the 15 -yearolds. Again, the 3-way association between linguistic group, age and response was not significant.

\section{Spanish vs. Basque identification}

The hierarchical log linear analysis of the responses on the Spanish vs. Basque identification task revealed only a highly significant association between response and linguistic group $\left(\chi^{2}(10)=58.55, p<0.0001\right)$. There were no associations involving age on this task. The data are presented in Table 5. Basque was the most common answer in both the Basque and the bilingual groups (65.5\% and $46.8 \%$ respectively), followed by more Basque than Spanish for both groups. In the Spanish group, the most frequently chosen card was both Basque and Spanish, followed by more Spanish than Basque.

\section{INSERT TABLE 5 ABOUT HERE}

\section{Evaluations of the national ingroup and selected national outgroups}

The children's attributions of adjectives to the seven national groups (Basque, Extremadurian, Spanish, French, Italian, British and German) were analysed in the following way. The 12 adjectives were first categorised on the following dimensions: clean (clean/dirty), friendly (friendly/unfriendly), clever (clever/stupid), work (hardworking/lazy), happy (happy/sad) and honest (honest/dishonest). The child's answers for each individual national group were then scored as follows: if the child chose neither adjective of a dimension to describe the group, a score of 0 was awarded; if the child chose only the negative adjective to describe the group, a score of 1 was awarded; if the child chose both the negative and the positive adjectives of a dimension to describe the group, a score of 2 was awarded; if the child chose only the positive adjective to describe the group, a score of 3 was awarded. These scores were then summed, and divided by the total number of dimensions which had been used by the child to evaluate 
that particular group. This scoring procedure therefore yielded an evaluation score for each individual target group on a scale which ranged from 1 to 3 . The higher the evaluation score, the more positively that group was evaluated on those particular dimensions which had been chosen and used by the child to describe the group.

The evaluation scores for the seven national groups were analysed using a principal components factor analysis with oblimin rotation. This revealed two factors: the first factor included the evaluations of French, Extremadurian, German, Spanish, Italian and British people (eigenvalue $=2.68 ; \%$ of variance explained $=38.3 \%$; factor loadings $=0.63$ and above), while the second factor consisted of the evaluations only of Basque people (eigenvalue $=1.07 ; \%$ of variance explained $=15.2 \%$; factor loading $=$ 0.92). These factors were called $N-B A S$ (for non-Basque) and $B A S$ (for Basque) respectively.

The six scores forming the $N-B A S$ factor scaled reliably (Cronbach's alpha = 0.75 ), and so a single mean evaluation score was derived by averaging these six scores. In order to ascertain whether there were any significant differences in the $B A S$ and $N$ $B A S$ scores as a function of either linguistic group or age, a 4 (age) x 3 (linguistic group) x 2 ( $B A S$ vs. $N-B A S)$ mixed analysis of variance was carried out, with independent groups on the first two factors and repeated measures on the third factor. There were no significant effects involving age. However, there was a significant main effect of $B A S$ vs. $N-B A S(F(1,197)=175.50, p<0.001)$. The mean scores are shown in Table 6, which reveals that the BAS scores were consistently higher than the $N-B A S$ scores in all three linguistic groups. There was also a significant main effect of linguistic group $(F(2,197)=3.75, p<0.05)$, but this was qualified by a significant interaction between linguistic group and $B A S$ vs. $N-B A S(F(2,197)=17.07, p<0.001)$. Post hoc Scheffe tests $(p<0.05)$ were used to explore these effects involving linguistic group. These revealed that the $N-B A S$ scores produced by the Basque speakers were significantly lower than the $N$-BAS scores produced by the Spanish speakers and the bilinguals, while the $B A S$ scores produced by the Basque speakers were significantly higher than the $B A S$ scores produced by the Spanish speakers. Thus, the use of Spanish in the home (by both Spanish speakers and bilinguals) is associated with more positive $N-B A S$ evaluations, while the exclusive use of Basque in the home is associated with more positive $B A S$ evaluations (compared with speakers who exclusively use Spanish in the home).

\section{INSERT TABLE 6 ABOUT HERE}

\section{The numbers of positive and negative adjectives attributed to}

\section{the seven national groups}

In order to examine the specific cognitive-developmental prediction that the number of negative adjectives attributed to the national ingroup, and the number of positive adjectives attributed to national outgroups, would increase between 6 and 12 years of age, seven additional ANOVAs were conducted on the adjectives. In these analyses, the number of positive and negative adjectives which had been attributed to each of the seven national groups individually were analysed using seven separate 4 (age) x 3 (linguistic group) x 2 (positive vs. negative adjectives) mixed ANOVAs. There were no significant main effects of age, and no significant interaction effects involving age, in any of these analyses. In other words, the number of positive and negative adjectives attributed to each individual national group showed no changes as a function of age, contrary to prediction. 


\section{Feelings about the national ingroup and selected}

$$
\text { national outgroups }
$$

The children's responses to the questions concerning whether they liked or disliked the members of each national group were scored in the following way: dislike a lot $=1$, dislike a little $=2$, don't know $=3$, like a little $=4$, like a lot $=5$. The scores for the seven national groups were analysed using a principal components factor analysis with oblimin rotation. The factor analysis revealed two factors. The first factor included feelings towards German, French, Italian, Extremadurian and British people (eigenvalue $=2.27 ; \%$ of variance explained $=32.5 \%$; factor loadings $=0.55$ and above). The second factor included Basque people (positive loading) and Spanish people (negative loading) (eigenvalue $=1.17$; $\%$ of variance explained $=16.7 \%$; factor loading for Basque $=0.84$, factor loading for Spanish $=-0.59$ ). These two factors were called Affect towards other European people and Affect toward Basque vs. Spanish people respectively.

The five scores which loaded onto the Affect towards other European people factor scaled reliably (Cronbach's alpha $=0.64$ ), and so a single mean affect score was derived by averaging these five scores. Because the Spanish affect scores were negatively loaded onto the second factor, they were reverse scored, and a mean score for the Affect toward Basque vs. Spanish people factor was then derived by averaging these reversed Spanish affect scores with the Basque affect scores.

In order to ascertain whether there were any significant differences in the two Affect scores as a function of either linguistic group or age, a 4 (age) x 3 (linguistic group) x 2 (Affect towards other European people vs. Affect towards Basque vs. Spanish people) mixed analysis of variance was carried out, with independent groups on the first two factors and repeated measures on the third factor. This revealed a significant main effect of age $(F(3,217)=5.52, p<0.001)$. Exploration of this main effect using post hoc Scheffe tests $(p<0.05)$ revealed that it was due to the nine-yearold children exhibiting significantly less positive affect than the fifteen-year-olds (overall mean affect for nine-year-olds $=3.14(S D=0.57)$, overall mean affect for fifteen-year-olds $=3.55(S D=0.43))$. This finding is curious, and difficult to explain. There were no other significant differences or effects involving age. However, there was a significant main effect of linguistic group $(F(2,217)=3.95, p<0.05)$, but this was qualified by a significant interaction between linguistic group and Affect towards other European people vs. Affect towards Basque vs. Spanish people $(F(2,217)=$ 20.73, $p<0.001)$. The means are shown in Table 7.

\section{INSERT TABLE 7 ABOUT HERE}

Post hoc Scheffe tests $(p<0.05)$ were used to explore these effects involving linguistic group. These tests revealed that the Basque speakers exhibited significantly lower affect towards other European people than the Spanish speakers and the bilinguals, and that the Spanish speakers exhibited significantly lower affect towards Basque people (and higher affect towards Spanish people) than the Basque speakers and the bilinguals. Thus, the use of Spanish as a family language (by both Spanish speakers and by bilinguals) is related to more positive affect towards other European peoples, while the use of Basque as a family language (by both Basque speakers and bilinguals) is associated with more positive affect towards Basque people (and lower affect towards Spanish people). 
The relationship between strength of national identification and positive distinctiveness

SIT postulates that when an individual identifies strongly with a particular social group, he or she is motivated to evaluate that group positively in comparison to salient outgroups, using appropriate dimensions of comparison in order to do so. Thus, the strength of identification with the national group should be related to the degree of positive distinctiveness which is attributed to that group vis-à-vis other national outgroups: the stronger the identification, the greater the level of positive distinctiveness attributed to the ingroup. This prediction was tested in the following way.

Firstly, the adjective evaluation scores which were obtained for the French, Extremadurian, German, Italian and British outgroups were subtracted from the adjective evaluation scores for the Basque group, producing five positive distinctiveness scores for the Basque group. These five scores were analysed using a principal components factor analysis with oblimin rotation, which revealed that they all loaded on to a single factor (eigenvalue $=2.80 ; \%$ of variance explained $=55.9 \%$ ) on which all variables loaded at 0.72 or above. As the five variables scaled reliably (Cronbach's alpha $=0.80$ ), a mean Basque positive distinctiveness score was derived.

Next, this positive distinctiveness score was correlated with the strength of Basque identification. This correlation was run only on those children who had spontaneously selected the Basque card as a self-description in the first selfcategorisation task (to ensure that only data from individuals who subjectively identified with this category as an ingroup were included in the correlation). The correlation between the strength of Basque identification and Basque positive distinctiveness was significant $(r=0.19, \mathrm{p}<0.05$; with age partialled out, $r=0.17, \mathrm{p}<$ $0.05)$.

Secondly, the adjective evaluation scores which were obtained for the French, German, Italian and British outgroups were subtracted from the adjective evaluation scores for the Spanish group, producing four positive distinctiveness scores for the Spanish group (Extremadurian was not used as a comparison group in this case, as it is a sub-group of the Spanish group). These four scores were analysed using a principal components factor analysis with oblimin rotation, which revealed that they all loaded on to a single factor (eigenvalue $=2.53 ; \%$ of variance explained $=63.2 \%$ ) on which all variables loaded at 0.79 or above. As the four variables scaled reliably (Cronbach's alpha $=0.81$ ), a mean Spanish positive distinctiveness score was derived.

Using only the data from that group of children who had spontaneously selected the Spanish card as a self-description in the first self-categorisation task, it was found that the Spanish positive distinctiveness score was significantly and positively correlated with the strength of Spanish identification $(r=0.35, \mathrm{p}<0.001$; with age partialled out, $r=0.32, p<0.001)$. Thus, in the case of both Basque and Spanish identification, there was support for the SIT prediction that the strength of identification is related to the positive distinctiveness attributed to the ingroup.

The relationship between strength of national identification and affective distinctiveness

Analogous analyses were conducted on the affect (like/dislike) scores. Firstly, the affect scores which were obtained for the French, Extremadurian, German, Italian and British outgroups were subtracted from the affect scores for the Basque group, 
producing five affective distinctiveness scores for the Basque group. These five scores were analysed using a principal components factor analysis with oblimin rotation, which revealed that they all loaded on to a single factor (eigenvalue $=2.97$; $\%$ of variance explained $=59.3 \%$ ) on which all variables loaded at 0.75 or above. As the five variables scaled reliably (Cronbach's alpha $=0.83$ ), a mean Basque affective distinctiveness score was derived. Using only the data from that group of children who had spontaneously selected the Basque card as a self-description in the first selfcategorisation task, it was found that this affective distinctiveness score was significantly and positively correlated with the strength of Basque identification ( $r=$ $0.30, p<0.001$; with age partialled out, $r=0.29, p<0.001$ ).

Secondly, the affect scores which were obtained for the French, German, Italian and British outgroups were subtracted from the affect scores for the Spanish group, producing four affective distinctiveness scores for the Spanish group. These four scores were analysed using a principal components factor analysis with oblimin rotation, which revealed that they all loaded on to a single factor (eigenvalue $=2.81 ; \%$ of variance explained $=70.2 \%$ ) on which all variables loaded at 0.81 or above. As these four variables scaled reliably (Cronbach's alpha $=0.86$ ), a mean Spanish affective distinctiveness score was derived. Using only the data from that group of children who had spontaneously selected the Spanish card as a self-description in the first selfcategorisation task, it was found that this Spanish affective distinctiveness score was significantly and positively correlated with the strength of Spanish identification $(r=$ $0.45, p<0.001$; with age partialled out, $r=0.41, p<0.001$ ). Thus, in the case of both Basque and Spanish identification, there was a significant and positive relationship between the strength of identification and the affective distinctiveness exhibited towards the ingroup.

\section{Discussion}

At the end of the Introduction, three predictions were outlined. It was predicted that: (1) there would be systematic variability in the national identifications exhibited by the children as a function of the language(s) spoken with the parents in the home environment; (2) there would be a reduction in ingroup bias between 6 and 12 years of age (the cognitive-developmental prediction); and (3) there would be a significant correlation between the strength of national identification and the positive distinctiveness ascribed to the ingroup (the social identity prediction). The findings will be discussed in relationship to each of these three predictions in turn.

Variability in the national identifications exhibited by the children

The study revealed that there were indeed pervasive differences in the children's national identifications as a function of their linguistic group. To summarise the findings first: the children who spoke only Spanish at home with their parents, when compared with the Basque-speaking children, were less likely to choose Basque as their first-choice self-description, were more likely to say that they came from Spain, were more likely to say they felt very Spanish, were less likely to say they felt very Basque, were more likely to say they were both Basque and Spanish or more Spanish than Basque, evaluated other national outgroups more positively, evaluated Basque people less positively, exhibited less positive affect towards Basque people (and more positive affect towards Spanish people), attributed lower positive and affective distinctiveness to Basque people, and attributed higher positive and affective distinctiveness to Spanish 
people.

By contrast, the children who spoke only Basque at home with their parents, when compared with the Spanish-speaking children, were more likely to choose Basque as their first-choice self-description, were more likely to say that they came from the Basque Country, were more likely to say they were not at all Spanish, were more likely to say they were very Basque, were more likely to say they were Basque rather than Spanish, evaluated other national groups less positively, evaluated Basque people more positively, exhibited less positive affect towards other national groups, exhibited more positive affect towards Basque people (and less positive affect towards Spanish people), attributed higher positive and affective distinctiveness to Basque people, and attributed lower positive and affective distinctiveness to Spanish people.

The bilingual children showed an intermediate pattern of national identification, sometimes resembling the Spanish group and sometimes resembling the Basque group. The bilingual children tended to be more similar to the Basque children in terms of their national identifications (see Tables 1-5), but more similar to the Spanish children in terms of their evaluations of and feelings towards national outgroups (see Tables 6 and 7).

Thus the children exhibited different patterns of both national identifications and national attitudes as a function of their linguistic group membership, presumably as a consequence of their exposure to, and internalisation of, the different national identifications and attitudes exhibited by their parents. A role for familial and/or socioenvironmental factors in the development of ethnic attitudes has recently been hypothesised by Black-Gutman \& Hickson (1996), Ocampo et al. (1997), and Cameron et al. (2001), and the present findings suggest that such factors may indeed be important in the development of national attitudes as well.

Note that in proposing this explanation of the observed differences between the three linguistic groups, it is not being suggested that the mere circumstance of speaking a particular language (or pair of languages) at home is itself the causal factor which determines the pattern of national identification which is exhibited by the child. Instead, the pattern of language use in the home is itself likely to be determined by the ideological choices and the value systems of the parents in regard to issues of national identification. Indeed, we would argue that language choice is used within the Basque community as an instrument of intergroup differentiation, with adult speakers using their choice of language as a tactical positioning tool which allows them to express their attitudes towards the objective intergroup conflicts (i.e. between Basques and Spaniards) existing within the context of the modern Spanish State (cf. Azurmendi et al., 1998; Elejabarrieta, 1994; Valencia et al., in press; Vila, 1996). Thus, it seems likely that parental national identifications, and parental linguistic tactical positionings and practices, are the underlying factors that determine both the language(s) which are spoken by their children in the home and the patterns of national identification which are acquired by their children. However, in order to test this hypothesis, future studies should assess parental identifications and attitudes in addition to their children's, to ascertain whether these factors do in fact make a larger contribution to their children's national identifications and attitudes than language use per se.

The cognitive-developmental prediction

On the basis of previous findings by Doyle et al. (1988), Powlishta et al. (1994), Doyle and Aboud (1995) and Barrett et al. (1999a), it had also been predicted that there 
would be a reduction in ingroup bias between 6 and 12 years of age. However, the overall picture which emerged from this study is that the children at all four ages exhibited remarkably similar patterns of response. It is especially noteworthy that the study failed to find any age-related changes in the overall evaluations of the national ingroup, in the overall evaluations of the national outgroups, in the affect expressed towards the ingroup, in the affect expressed towards the outgroups, or in the number of positive and negative adjectives attributed to ingroups and outgroups.

The findings of the present study therefore raise problems for the cognitivedevelopmental account of the development of intergroup attitudes. Aboud and her colleagues (Aboud, 1988; Doyle et al., 1988; Doyle \& Aboud, 1995) have argued that there are substantial changes in intergroup attitudes between 6 and 12 years of age. They postulate that an important feature of these changes is that at 6 years of age children tend to attribute mainly positive characteristics to members of their own ingroup, and mainly negative characteristics to members of outgroups; by 12 years of age children attribute a mixture of both positive and negative characteristics to both ingroups and outgroups. Thus, the reduction in ingroup bias which has been observed in previous studies to occur between 6 and 12 years of age is hypothesised to be due to a decrease in the perceived homogeneity of both ingroups and outgroups, and the increasing realisation with age that all social groups contain all kinds of people. However, in the present study, these kinds of age-related changes in the attribution of positive and negative characteristics in the adjective evaluation task did not occur. This finding casts doubt upon the generalisability of Aboud's explanation, and upon the cognitive-developmental hypothesis that the reduction in ingroup bias through middle childhood is due to an underlying cognitive shift in the way in which all large-scale social groups are conceptualised.

In fact, the findings of this study cast some doubt upon any developmental theory which presupposes that children's national attitudes develop in a similar way irrespective of the specific national context in which they are growing up. Such an account fails to provide a satisfactory explanation of why children growing up in some national contexts (e.g. England and Switzerland: Barrett et al., 1999a; Piaget \& Weil, 1951; Tajfel, 1966) exhibit substantial age-related changes in national attitudes, whereas children growing up in other national contexts (such as the Basque Country) do not exhibit any such changes. The findings of the present study imply that universalist accounts of the development of intergroup attitudes simply do not do justice to the complexities of the actual developmental data, which instead reveal very different patterns of development according to the specific national context involved (cf. the similar conclusions reached by Black-Gutman \& Hickson, 1996, and Ocampo, Knight \& Bernal, 1997, on the development of ethnic attitudes).

There were occasional differences which occurred in the children's responses as a function of age, but these tended to involve the children's self-categorisations and national identifications, rather than their intergroup attitudes. For example, the children's responses to the question If you were in America and someone asked you "where are you from?", what would you say? exhibited a significant association with age. Essentially, the younger children were more likely to give the name of their city in response to this question, while the older children were more likely to respond with either the Basque Country or Spain. This association of response with age may be due to the concrete local city environment being more salient to the younger children (cf. Piaget \& Weil, 1951), although it should be noted that very few children, even at the 
youngest age, selected their city identity as their first-choice self-description (see Table 1). An alternative explanation is that as children get older they are more likely to draw the inference that, because the initial premise of the question If you were in America contains a term referring to a country, the interviewer requires them to produce a term at an equivalent level of generality. By contrast, younger children may not be so attuned to this tacit implication of the question, and are therefore more likely to produce responses at other levels of generality, such as the name of their city.

Performance on both the Spanish and Basque identification tasks also showed age-related differences, with the number of don't know responses declining as a function of age. This is perhaps not surprising when the sense of national identity is only just beginning to emerge at 6 years of age. Such young children still clearly have many uncertainties about their own national identity, a problem which may be compounded in the Basque Country by the potential availability of both Basque and Spanish as national categories.

The social identity prediction

SIT proposes that representations of ingroups and outgroups are cognitively constructed by the individual in order to meet certain motivational needs, in particular the need for positive self-esteem. Thus, in cases where the individual identifies strongly with a particular social group, comparisons between that group and salient outgroups are made by the individual using dimensions on which the ingroup receives the more favourable judgements. This positive bias towards the ingroup, relative to the comparison outgroups, enables the individual to achieve positive self-esteem as a consequence of his or her membership of that more positively evaluated group. However, when an individual's subjective identification with the group is weak or absent, then these effects will not occur. SIT therefore predicts a relationship between the strength of ingroup identification and the degree of ingroup bias.

Consistent with this prediction, the present study found positive correlations between the strength of Basque identification and the degree of both positive and affective distinctiveness attributed to Basques, and between the strength of Spanish identification and the degree of both positive and affective distinctiveness attributed to Spaniards. Although these correlations were modest in size (ranging from 0.17 to 0.45 ), they are comparable in magnitude to the correlations which have been found in similar studies with adults (cf. Aharpour \& Brown, 2000; Hinkle \& Brown, 1990).

These correlations are particularly noteworthy given several features of the present study. Firstly, the study examined the children's judgements of five different outgroups (i.e. Extremadurian, French, Italian, British and German people), rather than just the one which has been used in many studies into children's judgement of ethnic groups (typically African American vs. European American). Secondly, the correlation emerged using measures which do not confound the assessment of ingroup and outgroup attitudes (cf. Cameron et al., 2001). Thirdly, the correlation was found in relationship to two different national identifications (i.e. both Basque and Spanish identification). Fourthly, the correlation was obtained on two different measures (i.e. a descriptive-evaluative measure using adjectives and an affective like-dislike measure). Fifthly, the correlation emerged despite the variability which occurred in the children's national identifications as a function of their linguistic group membership. Thus, this correlation between the strength of national identification and the positive distinctiveness attributed the national ingroup appears especially robust in the case of 
Basque children.

\section{Conclusions}

This study has shown that national identification in Basque children is associated with the language(s) spoken in the family home. It has also revealed that Basque children's evaluations of, and feelings towards, national ingroups and outgroups are associated with the home linguistic situation. Thus, in the Basque Country, the use of language is associated with different ways of thinking and feeling about national groups and this relationship applies not only in adults but also in children. The traditional cognitive-developmental account, which postulates that there is a reduction in ingroup bias between 6 and 12 years of age, is unable to explain the lack of agerelated changes in attitudes towards national ingroups and outgroups that was found in the present study. However, the study did yield evidence to support the prediction made by social identity theory, namely that the strength of national identification would be related to the positive distinctiveness ascribed to the national ingroup. The fact that this prediction was supported using both an evaluative and an affect measure, with respect to both Spanish and Basque identifications, and despite the variability in the national identifications which occurred within the sample as a function of the language used in the family home, suggests that this relationship is robust in these children. 


\section{References}

Aboud, F. 1988. Children and Prejudice. Oxford: Blackwell.

Abrams, D. 1990. How do group members regulate their behaviour? An integration of social identity and self-awareness theories. In D. Abrams \& M.A. Hogg (Eds.), Social Identity Theory: Constructive and Critical Advances (pp. 89-112). New York: Harvester Wheatsheaf.

Aharpour, S. \& Brown, R. 2000. Group identification and ingroup bias: a metaanalysis of tests in the Hinkle-Brown model. Unpublished paper, University of Kent, Canterbury, UK.

Azurmendi, M.J., Garcia, I. \& Gonzalez, J.L. 1998. Influencia del uso de las lenguas en contacto con la identidad social en la Comunidad Autónoma Vasca. Revista de Psicología Social, 13 (1), 3-10.

Barrett, M. 1996. English children's acquisition of a European identity. In G.M. Breakwell and E. Lyons (Eds.), Changing European Identities: Social Psychological Analyses of Social Change (pp. 349-369). Oxford: ButterworthHeinneman.

Barrett, M. 2001. The development of national identity: a conceptual analysis and some data from Western European studies. In M. Barrett, T. Riazanova, \& M. Volovikova (Eds.), Development of National, Ethnolinguistic and Religious Identities in Children and Adolescents (pp. 16-58). Moscow: Institute of Psychology, Russian Academy of Sciences.

Barrett, M. in press. Children's Knowledge, Beliefs and Feelings about Nations and National Groups. Hove, UK: Psychology Press.

Barrett, M., del Valle, A., Lyons, E., Vila, I., Monreal, P. \& Perera, S. 1999b. Bilingual children and the sense of national identity: the case of children living in Catalonia. Paper presented at the VIIIth International Congress for the Study of Child Language, Donostia, Basque Country, July 1999.

Barrett, M. \& Short, J. 1992. Images of European people in a group of 5-10 year old English schoolchildren. British Journal of Developmental Psychology, 10, 33963.

Barrett, M., Wilson, H. \& Lyons, E. 1999a. Self-categorization theory and the development of national identity in English children. Poster presented at the Biennial Meeting of the Society for Research in Child Development, Albuquerque, New Mexico, USA.

Bennett, M., Lyons, E., Sani, F. \& Barrett, M. 1998. Children's subjective identification with the group and ingroup favoritism. Developmental Psychology, 34, 902-909.

Bennett, M., \& Sani, F. (in press) The Development of the Social Self. New York: Psychology Press.

Bigler, R.S. \& Liben, L. 1993. A cognitive-developmental approach to racial stereotyping and reconstructive memory in Euro-American children. Child Development, 64, 1507-1519.

Black-Gutman, D. \& Hickson, F. 1996. The relationship between racial attitudes and social-cognitive development in children: an Australian study. Developmental Psychology, 32, 448-456.

Branscombe, N.R. \& Wann, D.L. 1994. Collective self-esteem consequences of outgroup derogation when a valued social identity is on trial. European Journal of Social Psychology, 24, 641-657. 
Cameron, J.A., Alvarez, J.M., Ruble, D.N. \& Fuligni, A.J. 2001. Children's lay theories about ingroups and outgroups: reconceptualizing research on prejudice. Personality and Social Psychology Review, 5, 118-128.

Davey, A. 1983. Learning to be Prejudiced. London: Edward Arnold.

Doyle, A.B. \& Aboud, F.E. 1995. A longitudinal study of white children's racial prejudice as a social-cognitive development. Merrill-Palmer Quarterly, 41, 209228.

Doyle, A.B., Beaudet, J. \& Aboud, F.E. 1988. Developmental patterns in the flexibility of children's ethnic attitudes. Journal of Cross-Cultural Psychology, 19, 3-18.

Elejabarrieta, F. 1994. Social positioning: a way to link social identity and social representations. Social Science Information, 33, 241-253.

Giles, H., Bourhis, R.Y. \& Taylor, D.M. 1977. Towards a theory of language in ethnic group relations. In H. Giles (Ed.), Language, Ethnicity and Inter-group Relations (pp. 146-170). London: Academic Press.

Grant, P.R. 1992. Ethnocentrism between groups of unequal power in response to perceived threat to valued resources and to social identity. Canadian Journal of Behavioural Science, 24, 348-370.

Grant, P.R. 1993. Reactions to intergroup similarity: examination of the similaritydifferentiation and similarity-attraction hypothesis. Canadian Journal of Behavioural Science, 25, 28-44.

Hinkle, S. \& Brown, R. 1990. Intergroup comparisons and social identity: some links and lacunae. In D. Abrams \& M.A. Hogg (Eds.), Social Identity Theory: Constructive and Critical Advances (pp. 48-70). Hemel Hempstead: Harvester Wheatsheaf.

Jahoda, G. 1962. Development of Scottish children's ideas and attitudes about other countries. Journal of Social Psychology, 58, 91-108.

Jaspers, J.M.F., van de Geer, J.P., Tajfel, H. \& Johnson, N. 1972. On the development of national attitudes in children. European Journal of Social Psychology, 2, 347-369.

Johnson, N., Middleton, M. \& Tajfel, H. 1970. The relationship between children's preferences for and knowledge about other nations. British Journal of Social and Clinical Psychology, 9, 232-240.

Katz, P.A. \& Zalk, S. 1978. Modification of children's racial attitudes. Developmental Psychology, 14, 447-461.

Kelly, C. 1988. Intergroup differentiation in a political context. British Journal of Social Psychology, 27, 321-327.

Lambert, W.E. \& Klineberg, O. 1967. Children's Views of Foreign Peoples: A CrossNational Study. New York: Appleton-Century-Crofts.

Middleton, M., Tajfel, H. \& Johnson, N. 1970. Cognitive and affective aspects of children's national attitudes. British Journal of Social and Clinical Psychology, 9, 122-134.

Mummendey, A., Klink, A. \& Brown, R. 2001. Nationalism and patriotism: national identification and out-group rejection. British Journal of Social Psychology, 40, 159-172.

Ocampo, K.A., Knight, G.P. \& Bernal, M.E. 1997. The development of cognitive abilities and social identities in children: the case of ethnic identity. International Journal of Behavioural Development, 21, 479-500. 
Perreault, S. \& Bourhis, R.Y. 1998. Social identification, interdependence and discrimination. Group Processes and Intergroup Relations, 1, 49-66.

Piaget, J. \& Weil, A.M. 1951. The development in children of the idea of the homeland and of relations to other countries. International Social Science Journal, 3, 561-578.

Powlishta, K.K., Serbin, L.A., Doyle, A.B. \& White, D.R. 1994. Gender, ethnic and body type biases: the generality of prejudice in childhood. Developmental Psychology, 30, 526-536.

Sachdev, I. \& Bourhis, R.Y. 1990. Language and social identification. In D. Abrams \& M.A. Hogg (Eds.), Social Identity Theory: Constructive and Critical Advances (pp. 211-229). Hemel Hempstead: Harvester Wheatsheaf.

Tajfel, H. 1966. Children and foreigners. New Society, 7, 9-11.

Tajfel, H. (Ed.) 1978. Differentiation between Social Groups: Studies in the Social Psychology of Intergroup Relations. London: Academic Press.

Tajfel, H. \& Jahoda, G. 1966. Development in children of concepts and attitudes about their own and other nations: a cross-national study. Proceedings of the XVIII ${ }^{\text {th }}$ International Congress in Psychology, Moscow, Symposium 36, 17-33.

Tajfel, H., Jahoda, G., Nemeth, C., Campbell, J. \& Johnson, N. 1970. The development of children's preference for their own country: a cross-national study. International Journal of Psychology, 5, 245-253.

Tajfel, H. \& Turner, J.C. 1986. The social identity theory of intergroup behaviour. In S. Worchel \& W.G. Austin (Eds.), Psychology of Intergroup Relations (pp. 724). $2^{\text {nd }}$ edition. Chicago: Nelson-Hall.

Valencia, J., Elejabarrieta, F., Perera, S., Reizabal, L., Barrett, M., Vila, I., Gil de Montes, L., Ortiz, G. \& M. Larrañaga in press. Conflictual national identities and linguistic strategies as positioning tools in children and adolescents. In Proceedings of the 5th International Conference on Social Representations, "New Constructions", Montreal, Canada, 2000.

Vaughan, G.M. 1964. The development of ethnic attitudes in New Zealand school children. Genetic Psychology Monographs, 70, 135-175.

Vila, I. 1996. Perspectives de futur de la immersió lingüística”. Veus Alternatives, 8, 30-35.

Williams, J.E. \& Morland, J.K. 1976. Race, Color, and the Young Child. Chapel Hill: University of North Carolina Press. 
Table 1: The frequency with which each of six possible self-categorisations was chosen as the most important, broken down by linguistic group.

\begin{tabular}{|c|c|c|c|}
\hline & $\begin{array}{c}\text { SPANISH } \\
\text { SPEAKERS }\end{array}$ & $\begin{array}{c}\text { BASQUE } \\
\text { SPEAKERS }\end{array}$ & BILINGUALS \\
\hline AGE & $\begin{array}{c}17 \\
(17.5 \%)\end{array}$ & $\begin{array}{c}15 \\
(17.2 \%)\end{array}$ & $\begin{array}{c}9 \\
(14.5 \%)\end{array}$ \\
\hline GENDER & $\begin{array}{c}43 \\
(44.3 \%)\end{array}$ & $\begin{array}{c}34 \\
(39.1 \%)\end{array}$ & $\begin{array}{c}21 \\
(33.9 \%)\end{array}$ \\
\hline CITY & $\begin{array}{c}7 \\
(7.2 \%)\end{array}$ & $\begin{array}{c}3 \\
(3.4 \%)\end{array}$ & $\begin{array}{c}6 \\
(9.7 \%)\end{array}$ \\
\hline BASQUE & $\begin{array}{c}14 \\
(14.4 \%)\end{array}$ & $\begin{array}{c}34 \\
(39.1 \%)\end{array}$ & $\begin{array}{c}25 \\
(40.3 \%)\end{array}$ \\
\hline SPANISH & $\begin{array}{c}11 \\
(11.3 \%)\end{array}$ & $\begin{array}{c}0 \\
(0 \%)\end{array}$ & $\begin{array}{c}0 \\
(0 \%)\end{array}$ \\
\hline EUROPEAN & $\begin{array}{c}5 \\
(5.2 \%)\end{array}$ & $\begin{array}{c}1 \\
(1.1 \%)\end{array}$ & $\begin{array}{c}1 \\
(1.6 \%)\end{array}$ \\
\hline
\end{tabular}


Table 2: The frequency of different responses to the question If you were in America and someone asked you "where are you from?", what would you say?, broken down by linguistic group.

\begin{tabular}{|c|c|c|c|}
\hline & $\begin{array}{c}\text { SPANISH } \\
\text { SPEAKERS }\end{array}$ & $\begin{array}{l}\text { BASQUE } \\
\text { SPEAKERS }\end{array}$ & BILINGUALS \\
\hline NAME OF CITY & $\begin{array}{c}44 \\
(45.4 \%)\end{array}$ & $\begin{array}{c}40 \\
(46.0 \%)\end{array}$ & $\begin{array}{c}26 \\
(41.9 \%)\end{array}$ \\
\hline $\begin{array}{l}\text { BASQUE } \\
\text { COUNTRY }\end{array}$ & $\begin{array}{c}21 \\
(21.6 \%)\end{array}$ & $\begin{array}{c}32 \\
(36.8 \%)\end{array}$ & $\begin{array}{c}25 \\
(40.3 \%)\end{array}$ \\
\hline SPAIN & $\begin{array}{c}29 \\
(29.9 \%)\end{array}$ & $\begin{array}{c}11 \\
(12.6 \%)\end{array}$ & $\begin{array}{c}8 \\
(12.9 \%)\end{array}$ \\
\hline EUROPE & $\begin{array}{c}2 \\
(2.1 \%)\end{array}$ & $\begin{array}{c}2 \\
(2.3 \%)\end{array}$ & $\begin{array}{c}1 \\
(1.6 \%)\end{array}$ \\
\hline DON'T KNOW & $\begin{array}{c}0 \\
(0 \%)\end{array}$ & $\begin{array}{c}1 \\
(1.1 \%)\end{array}$ & $\begin{array}{c}0 \\
(0 \%)\end{array}$ \\
\hline OTHER & $\begin{array}{c}1 \\
(1.0 \%)\end{array}$ & $\begin{array}{c}1 \\
(1.1 \%)\end{array}$ & $\begin{array}{c}2 \\
(3.2 \%)\end{array}$ \\
\hline
\end{tabular}


Table 3: The frequency with which each of the three possible levels of Spanish identification was chosen, broken down by linguistic group.

\begin{tabular}{|c|c|c|c|}
\hline & $\begin{array}{c}\text { SPANISH } \\
\text { SPEAKERS }\end{array}$ & $\begin{array}{l}\text { BASQUE } \\
\text { SPEAKERS }\end{array}$ & BILINGUALS \\
\hline $\begin{array}{l}\text { NOT AT ALL } \\
\text { SPANISH }\end{array}$ & $\begin{array}{c}7 \\
(7.2 \%)\end{array}$ & $\begin{array}{c}29 \\
(33.7 \%)\end{array}$ & $\begin{array}{c}22 \\
(36.1 \%)\end{array}$ \\
\hline $\begin{array}{l}\text { A LITTLE BIT } \\
\text { SPANISH }\end{array}$ & $\begin{array}{c}37 \\
(38.1 \%)\end{array}$ & $\begin{array}{c}26 \\
(30.2 \%)\end{array}$ & $\begin{array}{c}22 \\
(36.1 \%)\end{array}$ \\
\hline VERY SPANISH & $\begin{array}{c}36 \\
(37.1 \%)\end{array}$ & $\begin{array}{c}10 \\
(11.6 \%)\end{array}$ & $\begin{array}{c}10 \\
(16.4 \%)\end{array}$ \\
\hline DON'T KNOW & $\begin{array}{c}17 \\
(17.5 \%)\end{array}$ & $\begin{array}{c}19 \\
(22.1 \%)\end{array}$ & $\begin{array}{c}7 \\
(11.5 \%)\end{array}$ \\
\hline OTHER & $\begin{array}{c}0 \\
(0 \%)\end{array}$ & $\begin{array}{c}2 \\
(2.3 \%)\end{array}$ & $\begin{array}{c}0 \\
(0 \%)\end{array}$ \\
\hline
\end{tabular}


Table 4: The frequency with which each of the three possible levels of Basque identification was chosen, broken down by linguistic group.

\begin{tabular}{|c|c|c|c|}
\hline & $\begin{array}{c}\text { SPANISH } \\
\text { SPEAKERS }\end{array}$ & $\begin{array}{c}\text { BASQUE } \\
\text { SPEAKERS }\end{array}$ & BILINGUALS \\
\hline $\begin{array}{l}\text { NOT AT ALL } \\
\text { BASQUE }\end{array}$ & $\begin{array}{c}14 \\
(14.4 \%)\end{array}$ & $\begin{array}{c}4 \\
(4.6 \%)\end{array}$ & $\begin{array}{c}2 \\
(3.2 \%)\end{array}$ \\
\hline $\begin{array}{l}\text { A LITTLE BIT } \\
\text { BASQUE }\end{array}$ & $\begin{array}{c}35 \\
(36.1 \%)\end{array}$ & $\begin{array}{c}2 \\
(2.3 \%)\end{array}$ & $\begin{array}{c}9 \\
(14.5 \%)\end{array}$ \\
\hline $\begin{array}{c}\text { VERY } \\
\text { BASQUE }\end{array}$ & $\begin{array}{c}42 \\
(43.3 \%)\end{array}$ & $\begin{array}{c}74 \\
(85.1 \%)\end{array}$ & $\begin{array}{c}46 \\
(74.8 \%)\end{array}$ \\
\hline DON'T KNOW & $\begin{array}{c}6 \\
(6.2 \%)\end{array}$ & $\begin{array}{c}7 \\
(8.0 \%)\end{array}$ & $\begin{array}{c}5 \\
(8.1 \%)\end{array}$ \\
\hline
\end{tabular}


Table 5: The frequency with which each of the five possible levels of Basque vs. Spanish identification was chosen, broken down by linguistic group.

\begin{tabular}{|c|c|c|c|}
\hline & $\begin{array}{c}\text { SPANISH } \\
\text { SPEAKERS }\end{array}$ & $\begin{array}{l}\text { BASQUE } \\
\text { SPEAKERS }\end{array}$ & BILINGUALS \\
\hline BASQUE & $\begin{array}{c}20 \\
(20.6 \%)\end{array}$ & $\begin{array}{c}57 \\
(65.5 \%)\end{array}$ & $\begin{array}{c}29 \\
(46.8 \%)\end{array}$ \\
\hline $\begin{array}{l}\text { MORE BASQUE } \\
\text { THAN SPANISH }\end{array}$ & $\begin{array}{c}18 \\
(18.6 \%)\end{array}$ & $\begin{array}{c}14 \\
(16.1 \%)\end{array}$ & $\begin{array}{c}17 \\
(27.4 \%)\end{array}$ \\
\hline $\begin{array}{l}\text { BOTH BASQUE } \\
\text { AND SPANISH }\end{array}$ & $\begin{array}{c}25 \\
(25.8 \%)\end{array}$ & $\begin{array}{c}5 \\
(5.7 \%)\end{array}$ & $\begin{array}{c}10 \\
(16.1 \%)\end{array}$ \\
\hline $\begin{array}{l}\text { MORE SPANISH } \\
\text { THAN BASQUE }\end{array}$ & $\begin{array}{c}21 \\
(21.6 \%)\end{array}$ & $\begin{array}{c}6 \\
(6.9 \%)\end{array}$ & $\begin{array}{c}1 \\
(1.6 \%)\end{array}$ \\
\hline SPANISH & $\begin{array}{c}10 \\
(10.3 \%)\end{array}$ & $\begin{array}{c}3 \\
(3.4 \%)\end{array}$ & $\begin{array}{c}2 \\
(3.2 \%)\end{array}$ \\
\hline DON'T KNOW & $\begin{array}{c}3 \\
(3.1 \%)\end{array}$ & $\begin{array}{c}2 \\
(2.3 \%)\end{array}$ & $\begin{array}{c}3 \\
(4.8 \%)\end{array}$ \\
\hline
\end{tabular}


Table 6: Mean scores (and standard deviations) on the $N-B A S$ and $B A S$ evaluation factors.

\begin{tabular}{|c|c|c|c|}
\hline & Spanish speakers & Basque speakers & Bilinguals \\
\hline FACTOR 1: $N-B A S$ & $2.48(0.35)$ & $2.11(0.57)^{1}$ & $2.43(0.51)$ \\
\hline FACTOR 2: BAS & $2.79(0.42)$ & $2.93(0.20)^{2}$ & $2.86(0.31)$ \\
\hline
\end{tabular}

${ }^{1}$ Significantly different from the $N-B A S$ scores of the Spanish speakers and the bilinguals

${ }^{2}$ Significantly different from the $B A S$ scores of the Spanish speakers 
Table 7: Mean affect scores (and standard deviations) towards other European people and towards Basque vs. Spanish people.

\begin{tabular}{|c|c|c|c|}
\hline & Spanish speakers & Basque speakers & Bilinguals \\
\hline $\begin{array}{c}\text { FACTOR 1: AFFECT } \\
\text { TOWARDS OTHER } \\
\text { EUROPEAN PEOPLE }\end{array}$ & $3.46(0.78)$ & $2.99(0.91)^{1}$ & $3.39(0.77)$ \\
\hline $\begin{array}{c}\text { FACTOR 2: AFFECT } \\
\text { TOWARDS BASQUE } \\
\text { VS. SPANISH PEOPLE }\end{array}$ & $2.95(0.90)^{2}$ & $3.77(0.85)$ & $3.62(0.83)$ \\
\hline
\end{tabular}

\footnotetext{
${ }^{1}$ Significantly different from the Affect towards other European people scores of the Spanish speakers and the bilinguals

${ }^{2}$ Significantly different from the Affect towards Basque vs. Spanish people scores of the Basque speakers and the bilinguals
} 